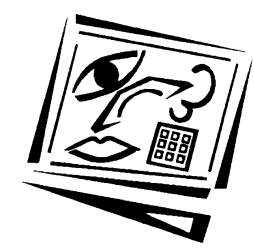

\title{
Issues involved in developing a project based online unit which enhances teamwork and collaboration
}

\author{
Rob Phillips \\ Teaching and Learning Centre, Murdoch University \\ Joe Luca \\ School of Communications and Multimedia, Edith Cowan University
}

\begin{abstract}
This paper presents the results of developmental research into the design of an online unit on Interactive Multimedia project management. The decision to offer the unit online was based on a requirement for the unit to be available in external mode, and an awareness that the traditional printbased delivery of material was not the most appropriate format considering the characteristics of a project-based unit.
\end{abstract}

The unit was designed around online collaborative activities, supported by content, in close alignment with Laurillard's (1993) model of the ideal teaching-learning process. An extension of this model was developed to explicitly allow for discussion between students.

Following a requirements analysis, WebCT was chosen as the course management tool by which the unit was made available to the students. The online activities used in the design of the course included: publishing personal web pages, online questionnaires, online seminars, the submission of relevant resources found by students, and general forum participation.

Finally, a framework for evaluating the merit of the online environment has been developed and will be briefly discussed.

\section{Introduction}

This paper discusses the factors and issues involved in developing an online unit to teach students how to manage the development of multimedia products. Since the major outcome and assessment item in the traditionally delivered unit was the production of a group-based multimedia product, the print-based distance education approach was 
inappropriate, because it provided limited opportunities for communication and collaboration. Our aim was to design an online environment, modelled around Laurillard's ideal teaching and learning process (Laurillard, 1993, p103, Laurillard, 1994), which maintained the quality of the educational experience for on-campus students. At the same time, the online environment was designed to blur the distinction between on- and off-campus students, by providing the same educational quality to external students - an experience far richer than could be expected in traditional print-mode.

\section{Background}

Final year undergraduate/postgraduate students enrolled in the Interactive Multimedia unit described in this paper are required to develop skills and expertise in project managing the development of multimedia products through the unit IMM3202/4201. Students learn about a range of project management methodologies in a traditional setting, and put these skills into practice in the creation of a team-based project that consolidates multimedia skills learnt in other units. Students learn to apply a range of project management skills appropriate to developing a multimedia web site. These include: developing appropriate project management models, performing a needs analysis, developing design specifications (storyboards, concept maps and rapid prototypes), conducting formative evaluation and addressing legal and intellectual property issues. Importantly, the group project encourages students to develop team and client collaboration skills.

In traditional format, prior to being offered online, the unit consisted of thirteen, three-hour class sessions. In the first nine sessions, students attend a lecture, which is followed by a group-based activity. Team skills and collaboration are continually promoted and reinforced throughout the unit. Teams of approximately four students are formed, necessitating the development of project management skills, communication skills and quality assurance systems.

There are three assignments: 'Analysis and Plan' worth 30 marks, 'Design' worth 35 marks and 'Final Product' worth 35 marks. Each of the assignments contains four marking components, in order of importance:

- a team mark based on the quality of the written assignments and final web product, addressing fixed criteria;

- an individual reflective report which encourages students to think about team and client issues they have identified as important and discuss how they would address them differently next time; 
- a mark awarded by the client on the basis of perceived team performance;

- a peer assessment mark, negotiated with the team. Marks can be subtracted from team members who are not performing and added to the score of other team members, the total marks awarded totalling zero. This encourages students to carefully consider their role and contribution in relation to the others while working in a team.

\section{Adapting to the online environment}

The incentive to deliver this unit in an online mode arose from the decision by the School to provide the Graduate Diploma of Interactive Multimedia in external mode. Four units had been developed in printbased mode in 1997, with online and CD-based materials as an adjunct, and IMM3202/ 4201 was required to be developed in 1998, for on-campus and external delivery.

The university had a strong and structured background in the development of print-based external studies programmes. External units require a Plan (administrative details), a Guide (course content modules) and a Reader (required readings) developed according to traditional Instructional Design principles (Herrington, 1996). However, we foresaw difficulties in trying to replicate the project-based and group-work aspects of this course by the essentially solitary, traditional, print-based distance education approach. Our review of the literature, on the other hand, indicated that it was possible to duplicate, to a large extent, the on-campus experience in online mode using collaboration and communication tools available on the Internet.

\section{Literature review}

A study by Marginson (Marginson, 1993) revealed that the three most desired characteristics of university graduates by business and industry in Australia were: communication skills; capacity to learn new skills and procedures; and capacity for cooperation and teamwork. The study also found that universities do not value these attributes as highly, ranking them seventh, fifth and eighth, respectively.

Since IMM is inherently multi-disciplinary and team-based (Phillips, 1997, p43) and because technology is changing so rapidly, the characteristics most valued by business and industry are especially important in interactive multimedia work environments. One of the features of the 
University's on-campus delivery of multimedia courses is the development of these graduate characteristics, and, consequently, many units are presented in a student-centred fashion which encourages group discussion, project work and independent learning of new software packages.

There is substantial literature about the use of the Internet as a collaborative tool rather than a medium for transmission of content (Collis, 1996; Harasim, 1993; Harasim, Hiltz, Teles, \& Turoff, 1995; Jonassen, Davidson, Collins, Campbell, \& Haag, 1995). Harasim et al. (1995) have examined how computer mediated communications can create the richness of an on-campus experience for off-campus students, using wellestablished and inexpensive technology. They identified a range of collaborative activities generated for the student by the teacher, such as online seminars, small group discussions, group presentations, debates and role plays.

Teles (1994) has elaborated on the cognitive apprenticeship model (Brown, Collins, \& Duguid, 1989) by identifying 'teleapprenticeship' activities such as mentoring and peer collaboration. Collis has discussed the establishment of integrated and collaborative online learning environments to foster the development of student teamwork and communication skills (Collis, 1997; van der Veen \& Collis, 1997).

An essential component of successful online educational activity is building a sense of community (Dillenbourg, 1995), for example, through a 'virtual cafe' (Harasim et al., 1995). Harasim (1993) has found that it is important to specifically design an online learning environment which encourages participation by students. A particular difficulty is that students are reluctant to contribute unless they have 'met' each other. One solution is for students to have some initial face-to-face contact (Harasim et al., 1995). Alternatively, students can initially meet by video conference (Pouw, van der Veen, \& Andernach, 1997; van der Veen, 1997) or simply by publishing home pages about themselves.

The literature review gave us confidence that an online version of the project management unit could be designed in a way which blurred the distinction between internal and external enrolment modes, offered more flexibility to our students, and yet enabled us to continue a high quality, student-centred learning experience. 


\section{Theoretical model of teaching and learning}

The methods used to teach the project management unit are closely aligned to Laurillard's model (Figure 1) of the ideal teaching-learning process (Laurillard, 1993, p103, Laurillard, 1994). Laurillard posits that learning consists of a theoretical part (top of Fig. 1), arising from "Discussion between teacher and student"; and an experiential part (bottom of Fig. 1), arising from "Interaction between student and world" where students interact with an environment created by the teacher. An important part of learning occurs when students link the theoretical and experiential parts, by reflecting on their understanding based on their experiences, and adapting their conceptual knowledge accordingly (right side of Fig. 1).

Laurillard argues that teachers should continually reflect on the success of their teaching and adapt their learning activities accordingly, as shown (left side of Fig. 1). The process of re-engineering the project management unit for online delivery is an adaptation based on our reflection about the strengths and weaknesses of the original unit structure.

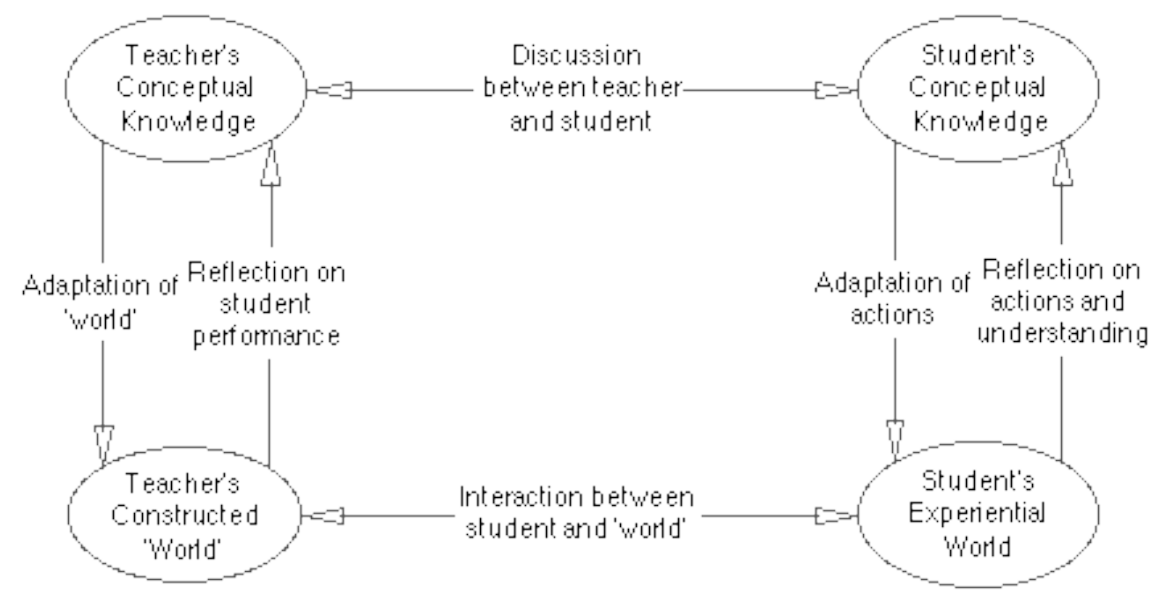

Figure 1: Laurillard's model of the ideal teaching-learning process (Laurillard, 1993)

A weakness in Laurillard's model is that it ignores the role of discussion between students in the learning process. Social constructivist learning theory (Vygotsky, 1978), on the other hand, argues that learning involves social discourse between peers. We present here an enhancement of 
Laurillard's model (Fig. 2), which explicitly allows for communication and discussion between students. We used the expanded Laurillard model as a blueprint for designing the online unit as follows:

- there is two-way discourse about conceptual issues of project management between teachers and students;

- the team project is a medium whereby students experience project management issues first hand;

- there is a close link between the conceptual and practical issues, mandated by the team-based project;

- the individual assessment encourages students to reflect on the applicability of project management methodology;

- students are offered many opportunities to build understanding by discussion with other students.

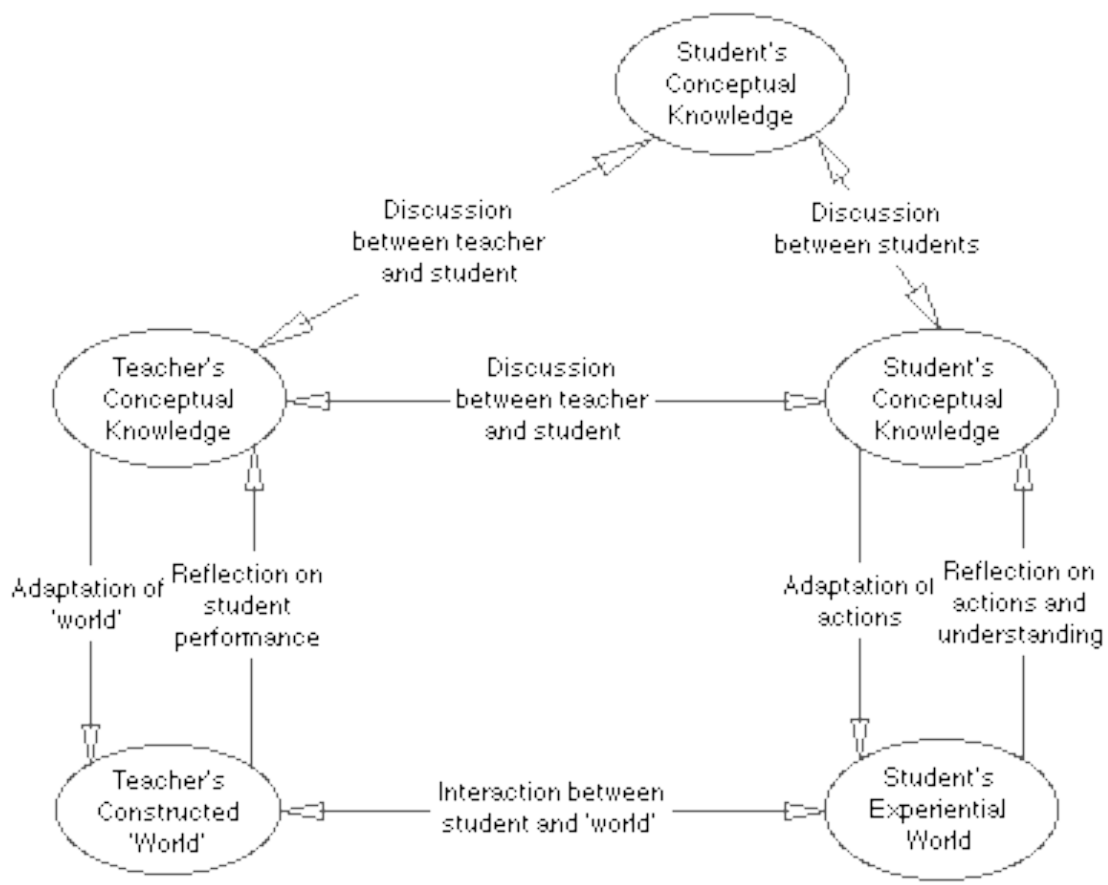

Figure 2. Adaptation of Laurillard's model of the ideal teaching-learning process which allows for communication between students. 
An evaluation of this unit is currently underway, in order to determine:

- the processes by which students use the online environment;

- the merit of the online environment by judging it against the design criteria;

- how teachers approach the use of the online environment - what experiences do they have?

We are also evaluating the way that students achieve the objectives of the unit - in particular, how much they understand project management methodologies. The expanded Laurillard model is being used as a framework for creating, categorising and analysing data arising from this evaluation. The results of the evaluation will be presented in a subsequent paper.

\section{Requirements of the online course}

The traditional distance education approach (transmitting printed or webbased study guides for individual study) addresses only one aspect of the ideal teaching and learning process, namely the transmission of the teacher's conceptual knowledge to the student. Our unit required a link between experiential and theoretical understanding, and development of teamwork and negotiation skills.

The online version of the unit was designed with a focus on collaborative activities, supported by the content-based resources of a Guide (online and print) and Reader (print only, for copyright reasons). A decision was made to limit the amount of online text as much as possible. The online text was generally quite brief and simply summarised the topic and directed students to other resources.

The online activities are described in detail in the following section. However, as part of the design of the activities, a requirements analysis was carried out to determine whether the activities were feasible, and what technological tools were available. The WebCT course management system (WebCT Educational Technologies, 1999) was able to provide the required functionality. The online activities and associated WebCT tools and functions are summarised in Table 1[1].

1 Project teams were also given access to functions which enabled students to work in real time to develop their projects. These were an online chat facility, and a shared electronic whiteboard. However, these tools were not built into structured activities. 
WebCT also enabled monitoring of student progress and discussion forum use. This was particularly helpful in identifying students who had not accessed course materials and were at risk of withdrawing.

Table 1: Online activities and associated WebCT tools

\begin{tabular}{|l|l|}
\hline Online activity & WebCT tool \\
\hline $\begin{array}{l}\text { Students to publish information about } \\
\text { themselves }\end{array}$ & $\begin{array}{l}\text { Individual presentation } \\
\text { areas (Home page tool) }\end{array}$ \\
\hline $\begin{array}{l}\text { Project teams to share documents, submit } \\
\text { team assignments and publish their final web- } \\
\text { based projects }\end{array}$ & $\begin{array}{l}\text { Group presentation area } \\
\text { tool }\end{array}$ \\
\hline Students to ask questions about general issues & $\begin{array}{l}\text { General discussion forum } \\
\text { (Bulletin Board tool) }\end{array}$ \\
\hline $\begin{array}{l}\text { Students to discuss set topics on a weekly } \\
\text { basis }\end{array}$ & $\begin{array}{l}\text { Specific discussion forum } \\
\text { (Bulletin Board tool) }\end{array}$ \\
\hline Teams to share work in progress & $\begin{array}{l}\text { Private discussion forum } \\
\text { (Bulletin Board tool) }\end{array}$ \\
\hline Access to online course materials & $\begin{array}{l}\text { HTML pages available } \\
\text { through the Path tool }\end{array}$ \\
\hline Students to record their own notes & Notes tool \\
\hline Links to external sites & Links tool \\
\hline $\begin{array}{l}\text { Students to publish resources which they have } \\
\text { located (references, URLs, etc.) }\end{array}$ & Bulletin Board tool \\
\hline
\end{tabular}

\section{Implementation of the online course}

In order to confirm the importance of the online activities in the minds of the students, we allocated marks to the most important activities. As in the traditional unit, each of the three assignments had four categories of assessment for the team development project: team assessment of the project and its documentation; a client mark; a project team consensus mark; and an individual reflective report. In the online unit, we added assessment of the theoretical aspects of project management through the marking of both group and individual online activities. The assessment mix is shown in Table 2 .

The major weekly activity was an online seminar in which one task group created and published a short summary paper on an aspect of project management, outlining the topic and raising issues for discussion. Students then moderated the discussion and published a synopsis paper at the end of the week. Eight marks were allocated for this. Nineteen marks 
were allocated for individual contributions to discussions, which included responding to online seminars, other scheduled activities, or assisting other students with technical knowledge or other advice.

Table 2. Mix of assessment in the online unit

\begin{tabular}{|l|c|}
\hline Assessment item & Mark \\
\hline Team assessment of project & 51 \\
\hline Client mark & 6 \\
\hline Team consensus mark & $\pm ? ?$ \\
\hline Individual reflective report & 16 \\
\hline Online seminars & 8 \\
\hline Contribution to discussions & 19 \\
\hline
\end{tabular}

Table 3 shows part of the Unit Outline for Semester 1, 1999. It illustrates how the course was structured around the concept of online activities, discussed in the following sections.

\section{Publish personal web page}

One of the prime considerations of success of an online course is the building up of a sense of community among the students (Dillenbourg, 1995, Harasim, 1993, Harasim et al., 1995). Many students need a sense of 'who the other person is' before feeling comfortable about contributing to discussion. In week one we encourage students to publish a light-hearted home page about themselves, as shown in this excerpt from the unit outline:

Introduce yourself to your fellow students by publishing a personal home page in the WebCT area. Feel free to include as much information about yourself as you want, including links to your real home page, if you have one.

Please include the following information on your page (take a light-hearted approach):

- your nickname

- your hobbies

- the most interesting event in your life

- the most embarrassing event in your life

- your life experiences in project management of any form

- any IMM project development experiences

- any other management experience

Lecturers and tutors also took part in this activity. 
Table 3. Excerpt from the Unit Outline for Semester 1, 1999

\begin{tabular}{|c|c|c|c|c|c|}
\hline Week & Topic & Activities & $\begin{array}{l}\text { Acti- } \\
\text { vity }\end{array}$ & Day & Who \\
\hline 1 & $\begin{array}{l}\text { Introduction } \\
\text { to project } \\
\text { management } \\
\text { course and } \\
\text { WebCT. }\end{array}$ & $\begin{array}{l}\text { - WebCT tutorial } \\
\text { - IMM } 4201 \text { web site access } \\
\text { and post message } \\
\text { to week } 1 \text { forum } \\
\text { - Publish personal web page } \\
\text { - Fill out online question- } \\
\text { naire on student skills } \\
\text { - Task group allocations }\end{array}$ & $\begin{array}{l}1.1 \\
1.2\end{array}$ & $\begin{array}{l}\mathrm{M} \\
\mathrm{M} \\
\mathrm{M}\end{array}$ & $\begin{array}{l}\text { All } \\
\text { All } \\
\text { Tutor }\end{array}$ \\
\hline 2 & $\begin{array}{l}\text { What is } \\
\text { project } \\
\text { management } \\
\text { ? }\end{array}$ & $\begin{array}{l}\text { - Assign project teams and } \\
\text { project topics } \\
\text { - Post message to week } 2 \\
\text { forum about "What is } \\
\text { project management?" } \\
\text { - Submit URL on project } \\
\text { management } \\
\text { - Online discussions on } \\
\text { posted topic } \\
\text { - Post synopsis }\end{array}$ & $\begin{array}{l}2.1 \\
2.2 \\
2.1 \\
2.1\end{array}$ & $\begin{array}{l}\text { M-F } \\
\text { Tu-Th } \\
\text { F }\end{array}$ & $\begin{array}{l}\text { Tutor } \\
\text { Tutor } \\
\text { All } \\
\text { All } \\
\text { Tutor }\end{array}$ \\
\hline 3 & $\begin{array}{l}\text { Team issues, } \\
\text { time sheet } \\
\text { categories, } \\
\text { project diary } \\
\text { and basic } \\
\text { quality } \\
\text { assurance. }\end{array}$ & 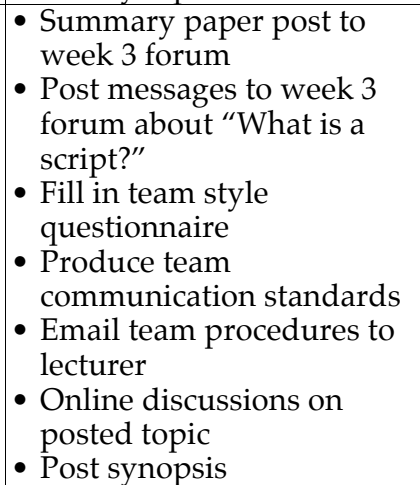 & $\begin{array}{l}3.4 \\
3.1 \\
3.2 \\
3.3 \\
3.3 \\
3.4 \\
3.4\end{array}$ & $\begin{array}{l}\text { M } \\
\text { M } \\
\text { M-F } \\
\text { F } \\
\text { Tu-Th } \\
\text { F }\end{array}$ & $\begin{array}{l}\text { Group } 1 \\
\text { All } \\
\text { All } \\
\text { All } \\
\text { Teams } \\
\text { All } \\
\text { Group } 1\end{array}$ \\
\hline
\end{tabular}

\section{Online Questionnaires}

WebCT's built-in survey forms were used occasionally to gather information from students. In week one students "Fill out online questionnaire on student skills" to assist the tutors in allocating students to project teams.

\section{Online Seminars by Task Groups}

As stated above, online seminars are a major activity used for developing conceptual knowledge. The tutors modelled the first week's online 
seminar activity, so that students knew what to do in subsequent weeks. Activity 2.1 was as follows:

This week your lecturer(s) will demonstrate the type of discussion required of each of you in subsequent weeks, by posting a discussion paper on Project Management Models and Life Cycles to the week 2 forum. Please read the lecturer's contribution and ask questions and make comments about it. Bear the following question in mind when you are constructing your responses: Why do you need Project Management Models? At the end of the week the lecturer will post a synopsis of the week's discussion.

Notice that students were required to contribute to the discussion and that a synopsis was given at the end of the week. In following weeks, a student task group prepared and presented the online seminar in a similar fashion, and answered questions posted by other individual students and lecturers. At the end of the week a synopsis of the week's comments was posted, as described by activity 3.4 below:

Task Group 1 is to write a short summary paper on group decision-making techniques, to be posted on Monday to the week 3 forum. All other students are expected to contribute their experiences and observations on this topic. Task Group 5 moderates the discussion and posts a final synopsis on Friday morning.

Each student task team was required to present one online seminar with moderation and a synopsis at the end of the week. It is important to note that the student task groups presenting the lecture were different to the project teams developing the multimedia product. This illustrates the continual reinforcement of collaboration and teamwork that is promoted in the unit.

\section{General forum messages}

Students were encouraged to make other contributions to the various discussion fora. Some were as part of the activity list, such as activity 3.1: "Post messages to week 3 forum about 'What is a script?".

Others were solicited by the tutors on an ad-hoc basis as issues arose from other discussions. Others came from students answering questions from other students about particular technical issues.

\section{Submit resources to the Class Resource List}

Originally, we had planned that one or more students would review each of the week's reading list items and submit summaries. Other students would search the web for relevant resources and submit them to the class. 
However, we became concerned that we might overload students with assessment activities, and incorporated most of these activities into the task group summaries.

One such activity survived from our ongoing reflection and adaptation of our course design, as activity 2.2:

Search the literature and the Web for case studies on Project Management. A good starting point is this week's readings and URLs. Write a two paragraph summary of the case study, and submit the summary and the URL/ reference to the Class Resource List. You should try to focus on IMM projects, but generally applicable information from any type of project management is acceptable.

\section{Conclusion}

This paper has described the process of designing an online unit supporting teamwork in learning project management methodologies for developing interactive multimedia. The unit was designed according to Laurillard's ideal model of teaching and learning, extended to include discussion between students. The most important factor in the design was the creation of student-centred online activities which aimed to promote discussion and reflection.

A framework for evaluation of the online unit has been developed. It will evaluate the merit of the online environment, ie. the process by which IMM3202/4201 is made available to students and what might be done to improve it. The study will also evaluate the outcomes achieved by students studying the unit. Data has been gathered from a range of sources and is currently being analysed. The results of the analysis, to be published in a subsequent paper, will be used to determine improvements to the way the unit is being taught.

\section{Acknowledgments}

The authors would like to thank Christine Bailey, Jennie Bickmore-Brand, Eva Dobozy, Romana Pospisil and Angela Smith for their helpful comments on this manuscript.

\section{References}

Brown, J. S., Collins, A., \& Duguid, P. (1989). Situated Cognition and the Culture of Learning. Educational Researcher, 18(1), 32-42.

Collis, B. (1996). Tele-learning in a Digital World: The Future of Distance Learning. International Thomson Computer Press. 
Collis, B. (1997). Supporting project-based collaborative work via a world wide web environment. In B. H. Khan (Ed.), Web-Based Instruction (pp. 213-219). Englewood Cliffs, New Jersey: Educational Technology Publications.

Dillenbourg, P. S. (1995). Collaborative learning and the Internet. [verified $13 \mathrm{Jul}$ 2000] http:/ / tecfa.unige.ch / tecfa/ tecfa-research/CMC/colla/iccai95_1.html

Harasim, L. (1993). Collaborating in Cyberspace: Using computer conferences as a group learning environment. Interactive Learning Environments, 3(2), 119-130.

Harasim, L., Hiltz, S. R., Teles, L., \& Turoff, M. (1995). Learning Networks- a Field Guide to Teaching and Learning Online. Cambridge Massachusetts: The MIT Press.

Herrington, J. (1996). Creating effective learning environments in print: A guide for lecturers and designers of independent study materials. Perth, Western Australia: Edith Cowan University.

Jonassen, D., Davidson, M., Collins, C., Campbell, J., \& Haag, B. B. (1995). Constructivism and computer-mediated communication in distance education. The American Journal of Distance Education, 9(2), 7-26.

Laurillard, D. M. (1993). Rethinking University Teaching: A Framework for the Effective Use of Educational Technology. London: Routledge.

Laurillard, D. M. (1994). Multimedia and the changing experience of the learner. Paper presented at the Asia Pacific Information Technology in Training and Education Conference, Brisbane, Australia.

Lotus Corp. (1998). Learning Space: Distributed Collaborative Learning. http: / / www.lotus.com/home.nsf/tabs / learnspace/[verified 13 Jul 2000]

Marginson, S. (1993). Arts, Science and Work. Canberra: Department of Employment Education and Training, Evaluations and Investigations Programme.

Phillips, R. (1997). The Developer's Handbook to Interactive Multimedia - A Practical Guide for Educational Applications. London: Kogan Page.

Pouw, C. L. M., van der Veen, J. T., \& Andernach, J. A. (1997). International TeleProject Groups in Higher Education (Internal Report ). Twente, The Netherlands: University of Twente.

Teles, L. (1994). Cognitive Apprenticeships on Global Networks. In L. Harasim (Ed.), Global Networks - Computers and International Communication (pp. 271-281). Cambridge, Mass.: The MIT Press.

van der Veen, J. T. (1997). Use of videoconferences to initiate contact within a new group of students. Personal communication. 
van der Veen, J. T., \& Collis, B. (1997). Telematic tools to support group projects in higher education. Paper presented at the Ed-Media 97 Conference, Calgary Canada.

Vygotsky, L. S. (1978). In M. Cole, V. John-Steiner, S. Scribner, \& E. Souberman (Eds.), Mind in Society. Cambridge, Mass: Harvard University Press.

WBT Systems. (1998). TopClass Overview.

http: / / www.wbtsystems.com/index.html [verified 13 Jul 2000]

WebCT Educational Technologies. (1999). WebCT: World Wide Web Course Tools. http:/ / www.webct.com/ [verified 13 Jul 2000]

Rob Phillips, Teaching and Learning Centre, Murdoch University, Murdoch WA 6150.r.phillips@murdoch.edu.au

Joe Luca, School of Communications and Multimedia, Edith Cowan University, Mt Lawley WA 6050.j.luca@cowan.edu.au 